\title{
Transarterial Embolization of Intracranial Arteriovenous Fistulas with Large Venous Pouches in the Form of Venous Outlet Ectasia and Large Venous Varix or Aneurysm : Two Centers Experience
}

\author{
Mohamed Adel Deniwar, ${ }^{1}$ Saima Ahmad, ${ }^{2}$ Ashraf Ezz Eldin ${ }^{1}$ \\ Department of Neurosurgery, Mansoura University Hospitals, Mansoura University, Mansoura, Egypt \\ Department of Diagnostic and Interventional Neuroradiology, ${ }^{2}$ Lahore General Hospital, Post Graduate Medical Institute, Ameer-ud-Din \\ Medical College, Lahore, Pakistan
}

Objective : There are different types of cerebral vascular malformations. Pial arteriovenous fistulas (PAVFs) and dural arteriovenous fistulas (DAVFs) are two entities; they consist of one or more arterial connections to a single venous outlet without a true intervening nidus. The high turbulent flow of PAVFs and aggressive DAVFs with cortical venous reflux can result in venous outflow varix and aneurysmal dilatation. They pose a significant challenge to transvenous embolization (TVE), stereotactic radiosurgery, and surgical treatment. We aim to share our centers' experience with the transarterial embolization (TAE) for arteriovenous fistulas (AVFs) with large venous pouches and to report the outcome.

Methods : The authors' two institutions' databases were retrospectively reviewed from February 2017 to February 2021. All patients with intracranial high flow PAVFs and aggressive DAVFs with venous outlet ectasia and large venous varix and were treated by TAE were included.

Results : Fifteen patients harboring 11 DAVFs and four PAVFs met our inclusion criteria. All patients underwent TAE in 17 sessions. Complete angiographic obliteration was achieved after 14 sessions in 12 patients (80\%). Four patients (25\%) had residual after one TAE session. Technical failure was documented in one patient (6.7\%). Fourteen patients (93.3\%) had favorable functional outcome (modified Rankin score 0-2).

Conclusions : TAE for high flow or aggressive intracranial AVFs is a safe and considerable treatment option, especially for those associated with large venous pouches that are challenging and relatively high-risk for TVE.

Key Words : Theraputic embolization · Endovascular · Intracranial arteriovenous fistulas with venous varix · Arteriovenous fistulas.

\section{INTRODUCTION}

There are different types of cerebral vascular malforma- tions. Pial arteriovenous fistulas (PAVFs) are rare entities where one or more pial arteries communicate directly with a cortical vein, accounting for $1.6 \%$ of all vascular lesions ${ }^{9,11,17)}$.

- Received : May 12, 2021 •Revised : June 19, 2021 • Accepted : July 14, 2021

- Address for reprints : Mohamed Adel Deniwar

Department of Neurosurgery, Mansoura University Hospitals, Mansoura University, 60 Algomhria Street, Mansoura, Dakahlia Governate 35516, Egypt

Tel : +201114431031, Fax : +202267016, E-mail : mohameddeniwar@mans.edu.eg, ORCID : https://orcid.org/0000-0002-6337-4072

This is an Open Access article distributed under the terms of the Creative Commons Attribution Non-Commercial License (http://creativecommons.org/licenses/by-nc/4.0) which permits unrestricted non-commercial use, distribution, and reproduction in any medium, provided the original work is properly cited. 
Dural arteriovenous fistulas (DAVFs) are abnormal connections between dural venous sinuses and dural or pachymeningeal branches of the internal carotid, external carotid, and vertebral arteries account for $10-15 \%$ of all intracranial arteriovenous malformations. Both PAVFs and DAVFs are distinct from the more common cerebral arteriovenous malformations; they consist of one or more arterial connections to a single venous outlet without a true intervening nidus ${ }^{16-18)}$.

The high turbulent flow of PAVFs can result in venous outflow varix and aneurysmal dilatation ${ }^{10,12,26)}$. The same sequence can occur with aggressive DAVFs (Borden type III, Cognard type IIb-V) with cortical venous reflux. Both can lead to subsequent cerebral venous hypertension and hemorrhage ${ }^{4,6,8}$. Treatment for such type of fistulas is inevitable and includes endovascular treatment, surgery, or stereotactic radiosurgery (SRS). The transvenous approach has been significantly considered by neurointerventionists in the past few years, especially in fistulas with multiple small feeders ${ }^{12-15)}$. However, the high flow arteriovenous fistulas (AVFs) with venous outflow dilatation, varix, and even aneurysms pose a significant challenge to transvenous embolization (TVE), SRS, and surgical treatment given to the fragility and long length of the venous access, and its deep location in some cases ${ }^{5,7,9,11-13,21,28)}$.

Our study aims to share our centers' experience with the transarterial approach in embolization of PAVFs and DAVFs associated with venous outlet ectasia and reporting the outcome.

\section{MATERIALS AND METHODS}

After Institutional Review Board approval was obtained (with code number : R.21.02.1228 and 161), the authors' two institutions' databases were retrospectively reviewed for intracranial arteriovenous fistulas from February 2017 to February 2021. Informed written consent was exempted, as it is a retrospective study.

\section{Inclusion criteria}

All of included intracranial AVFs were considered challenging to other treatment options as surgery, SRS or TVE given to the fragility and long length of the venous access, and its deep location in some cases. We did include all patients with intracranial high flow PAVFs and aggressive DAVFs that were associated with venous outlet ectasia and large venous varix or aneurysm accompanied with or without venous hypertension and were treated with endovascular transarterial embolization (TAE) in the study. Clinical presentation, location, type, agent and techniques used, complications, and clinical and radiological follow-up were included.

\section{Exclusion criteria}

We did exclude patients with direct carotid-cavernous fistulas, galenic venous malformations, and dural arteriovenous malformations in neonates. We consider those patients diagnosed with special pathological entities and have well-recognized and established therapeutic protocols ${ }^{3,19,24}$.

\section{RESULTS}

\section{Patient's characteristics}

Fifteen patients harboring 11 (Cognard type IIb-V) DAVFs and four (single hole) PAVFs met our inclusion criteria. Seven were females, and eight males. Their ages ranged from 4.5 to 65 years old (mean, 34.7 years). Headache $(87 \%)$ and tinnitus (40\%) were the most prevalent presentations, while six patients (40\%) developed intracranial hemorrhage (ICH). Only one patient required the surgical evacuation of ICH. None of these patients had prior treatment for the AVF (Tables 1 and 2).

\section{Technical aspects of TAE}

All patients underwent TAE using the EVOH copolymer (Onyx-18, Medtronic, Minneapolis, MN, USA; or Squid-12, Emboflu, Gland, Switzerland) or (n-butyl cyanoacrylate [NBCA] glue mixture with tantalum) in 17 sessions. It was accomplished in one session in 10 patients (66.7\%) and two sessions in two patients (13.3\%). Arterial inflow control during TAE was sought in five patients (33.3\%) (Table 3).

\section{Outcomes}

Complete angiographic obliteration was achieved after 14 sessions in 12 patients (80\%) as two of the patients underwent another TAE session. Technical failure was documented in one patient (6.67\%) and underwent another TAE session. Four patients (25\%) showed residual on angiography after one TAE session; one had another session of TAE and three patients are planned to have further treatment with TVE. Technical complication (Alopecia errata) occurred in only one patient 
Table 1. Patients demographics

\begin{tabular}{|c|c|c|c|c|c|}
\hline $\begin{array}{r}\text { Case } \\
\text { No. }\end{array}$ & $\begin{array}{c}\text { Age } \\
\text { (years) }\end{array}$ & Sex & Chief complaint & $\begin{array}{l}\text { Intracranial } \\
\text { hemorrhage }\end{array}$ & Type of AVF \\
\hline 1 & 13 & Male & Headache, cerebellar ataxia, dysarthria, and lower cranial nerves manifestations & No & DAVF \\
\hline 2 & 16 & Female & Headache and epilepsy & No & PAVF \\
\hline 3 & 65 & Male & Headache, tinnitus and disturbed conscious level at hospital presentation & Yes & DAVF \\
\hline 4 & 55 & Male & Headache, tinnitus and disturbed conscious level at hospital presentation & Yes & DAVF \\
\hline 5 & 50 & Male & Headache, epilepsy and tinnitus & Yes & DAVF \\
\hline 6 & 38 & Female & Headache, left side motor weakness and disturbed conscious level at hospital presentation & Yes & DAVF \\
\hline 7 & 50 & Male & Headache, diplopia, proptosis, chemosis and deterioration of vision & No & DAVF \\
\hline 8 & 7 & Female & Epilepsy & No & PAVF \\
\hline 9 & 4.5 & Male & Developmental delay and epilepsy & No & PAVF \\
\hline 10 & 39 & Female & Headache, and disturbed conscious level at hospital presentation & Yes & DAVF \\
\hline 11 & 55 & Male & Headache, tinnitus and disturbed conscious level at hospital presentation & Yes & DAVF \\
\hline 12 & 12 & Male & Headache & No & PAVF \\
\hline 13 & 15 & Female & Headache, diplopia, and proptosis & No & DAVF \\
\hline 14 & 56 & Female & Headache, epilepsy and tinnitus & Yes & DAVF \\
\hline 15 & 45 & Female & Headache and tinnitus & No & DAVF \\
\hline
\end{tabular}

AVF : arteriovenous fistula, DAVF : dural arteriovenous fistula, PAVF : pial arterioveous fistulas

Table 2. Radiological findings of the included fistulas

\begin{tabular}{|c|c|c|c|c|c|c|}
\hline $\begin{array}{r}\text { Case } \\
\text { No. }\end{array}$ & $\begin{array}{l}\text { Fistulous connection } \\
\text { side/site }\end{array}$ & $\begin{array}{l}\text { Arterial feeders, meningeal and } \\
\text { parenchymal branches of }\end{array}$ & Ectatic venous outlet & $\begin{array}{l}\text { Dural sinus } \\
\text { thrombosis }\end{array}$ & $\begin{array}{c}\text { Cortical } \\
\text { venous } \\
\text { reflux }\end{array}$ & $\begin{array}{c}\text { Venous } \\
\text { varix or } \\
\text { aneurysm }\end{array}$ \\
\hline 1 & Left transverse sinus & Left PCA, MMA, IMA, PA, OA and B\&C & Bilateral TS and right SS and IJV & Yes & Yes & Yes \\
\hline 2 & Left occipital lobe & Left PCA (P3 segment) & Left occipital vein, SS and IJV & No & No & Yes \\
\hline 3 & Left tentorium cerebelli & Right PCA, MMA, IMA, PA, OA and MHT & Right TS, SS and IJV & No & Yes & Yes \\
\hline 4 & Right transverse sinus & Right $P A, O A$ and $B \& C$ & Right TS, SS and IJV & No & Yes & No \\
\hline 5 & $\begin{array}{l}\text { Left sigmoid jugular } \\
\text { junction }\end{array}$ & Bilateral MMA, left MHT, PA and OA & Left TS, SS and IJV & No & Yes & No \\
\hline 6 & Right transverse sinus & Bilateral MMA, right MHT, $\mathrm{PA}$ and $\mathrm{OA}$ & Right TS, SS and IJV & Yes & Yes & Yes \\
\hline 7 & Left intraorbital & Left IMA and OPA & Left SOV and IOV & No & Yes & Yes \\
\hline 8 & Left Parietal lobe & Left MCA (post central branch) & Left cortical vein and SSS & No & No & Yes \\
\hline 9 & $\begin{array}{l}\text { Left frontotemporal } \\
\text { (perisylvian) }\end{array}$ & Left MCA (M3) (Sylvain branch) & Left vein of Labbe, SPS, SS and IJV & No & No & Yes \\
\hline 10 & $\begin{array}{l}\text { Left ethimoidal (anterior } \\
\text { cranial fossa) }\end{array}$ & Left anterior flax artery (OPA) & Left cortical frontal vein and SSS & No & Yes & Yes \\
\hline 11 & Left transverse sinus & Left MMA IMA, PA and OA & Left TS, SS and IJV & No & Yes & No \\
\hline 12 & Right parietal lobe & Right MCA (M4 segment) & Right cortical vein, SSS & No & Yes & Yes \\
\hline 13 & Left cavernous sinus & Left cavernous ICA, MHT, MMA and IMA & Left CS, SOV, SPiS and Sylvain vein & No & No & Yes \\
\hline 14 & Right transverse sinus & Right MMA, MHT, PA, OA and B\&C & Right TS, SS and IJV & Yes & Yes & Yes \\
\hline 15 & $\begin{array}{l}\text { Left transverse sigmoid } \\
\text { junction }\end{array}$ & Right MMA, MHT, PA, OA and B\&C & Left TS, SS and IJV & No & Yes & Yes \\
\hline
\end{tabular}

PCA : posterior cerebral artery, MMA : middle meningeal artery, IMA : internal maxillary artery, PA : periauricular artery, OA : occipital artery, B\&C : artery of Bernasconi and Cassenari, TS : transverse sinus, SS : sigmoid sinus, IJV : internal jugular vein, MHT : meningiohypophyseal trunk, OPA : ophthalmic artery, SOV : superior ophthalmic vein, IOV : inferior ophthalmic vein, SSS : superior sagittal sinus, SPS : superior petrosal sinus, CS : cavernous sinus, SPiS : sphenoparietal sinus 
TAE of AVFs with Large Venous Pouches | Deniwar MA, et al.

Table 3. Summary of the TAE techniques used

\begin{tabular}{|c|c|c|c|c|}
\hline Case No. & Procedure of TAE & Arterial inflow control using & Microcatheter & Embolization material* \\
\hline 1 & One session of onyx embolization & Scepter C balloon catheter & $\begin{array}{l}\text { Detachable tip Apollo } 3 \mathrm{~cm} \text { and } \\
\text { scepter C balloon catheter }\end{array}$ & Onyx \\
\hline 2 & $\begin{array}{l}\text { Two session (first double } \\
\text { microcatheter interlocking coil } \\
\text { embolization \& second onyx } \\
\text { embolization after } 2 \text { weeks) }\end{array}$ & HyperGlide balloon & $\begin{array}{l}\text { Excelsior SL } 10 \text { and flow guided } \\
\text { Marathon }\end{array}$ & Axium 3D coils, onyx \\
\hline 3 & One session of glue embolization & None & Flow guided Sonic & NBCA glue (mixed with tantalum) \\
\hline 4 & One session of glue embolization & None & Flow guided magic & NBCA Glue (mixed with tantalum) \\
\hline 5 & One session of glue embolization & None & Flow guided magic & NBCA Glue (mixed with tantalum) \\
\hline 6 & One session of glue embolization & None & Flow guided magic & NBCA glue (mixed with tantalum) \\
\hline 7 & One session of onyx embolization & $\begin{array}{l}\text { Scepter } \mathrm{C} \text { balloon catheter and } \\
\text { pressure cooker technique }\end{array}$ & Scepter C balloon catheter & Onyx \\
\hline 8 & One session of glue embolization & None & Flow guided magic & NBCA glue (mixed with tantalum) \\
\hline 9 & One session of glue embolization & None & Flow guided magic & NBCA glue (mixed with tantalum) \\
\hline 10 & One session of onyx embolization & None & Detachable tip Apollo 3 cm & Onyx \\
\hline 11 & One session of onyx embolization & Scepter C balloon catheter & Scepter $\mathrm{C}$ balloon catheter & Onyx \\
\hline 12 & One session of onyx embolization & Scepter $\mathrm{C}$ balloon catheter & Scepter C balloon catheter & Onyx \\
\hline 13 & One session of onyx embolization & None & Flow guided magic & Onyx \\
\hline \multirow[t]{2}{*}{14} & \multirow{2}{*}{$\begin{array}{l}\text { Two session (first squid \& second } \\
\text { onyx embolization after } 1 \text { year) }\end{array}$} & \multirow[t]{2}{*}{ None } & Flow guided sonic & Squid \\
\hline & & & Flow guided magic & NBCA glue (mixed with tantalum \\
\hline 15 & One session of onyx embolization & None & Detachable tip Apollo $3 \mathrm{~cm}$ & Onyx \\
\hline
\end{tabular}

*The choice of the embolizing material was according to the interventionist preference mainly and its availability at the time of procedure. ${ }^{\dagger}$ Applying a coil proximal to the injecting microcatheter in the arterial feeder. TAE : transarterial embolization, NBCA : n-butyl cyanoacrylate

Table 4. Summary of the outcomes

\begin{tabular}{|c|c|c|c|c|}
\hline Case No. & Angiographic occlusion after TAE & Technical complication & Follow up duration (months) & Clinical outcome (mRS) \\
\hline 1 & Moderate residual & None & $1-16$ & 3 \\
\hline 2 & Complete occlusion after two sessions & Alopecia areata & 6 & 0 \\
\hline 3 & Complete occlusion & None & $2-36$ & 0 \\
\hline 4 & Complete occlusion & None & 36 & 0 \\
\hline 5 & Complete occlusion & None & 12 & 0 \\
\hline 6 & Complete occlusion & None & $3-24$ & 3 \\
\hline 7 & Complete occlusion & None & 3 & 0 \\
\hline 8 & Complete occlusion & None & 6 & 0 \\
\hline 9 & Complete occlusion & None & 12 & 2 \\
\hline 10 & Complete occlusion & None & 3 & 0 \\
\hline 11 & Complete occlusion & None & 6 & 2 \\
\hline 12 & Complete occlusion & None & 6 & 0 \\
\hline 13 & Moderate residual & None & 12 & 1 \\
\hline 14 & $\begin{array}{l}\text { Moderate residual after first session and complete } \\
\text { occlusion at final session }\end{array}$ & None & $1-12$ & 0 \\
\hline 15 & Moderate residual & None & 3 & 1 \\
\hline
\end{tabular}

TAE : transarterial embolization, mRS : modified Rankin score 
(6.7\%). Fourteen patients (93.3\%) had favorable functional outcome according to the modified Rankin score (mRS; 0-2). One patient had improved after TAE from mRS 4 to 3 . Follow-up duration (1 to 36 months) (Table 4 ).

\section{Case illustration}

\section{Case 1}

Male aged 13 years old manifested by disabling cerebellar and progressive venous hypertension signs. A digital subtraction angiogram (DSA) revealed a Congard type IV DAVF at the left transverse sinus. It was supplied by : ipsilateral middle meningeal artery (MMA) and occipital artery (OA), posterior auricular artery, artery of Bernasconi and Cassenari, and pachymeningeal branches of the posterior cerebral artery (PCA). It drained into the ectatic transverse on both sides, and right sigmoid sinuses and internal jugular vein. The left sig- moid sinus was thrombosed and occluded. Cortical venous reflux was evident too (Fig. 1). The patient underwent one session of TAE with onyx for pachymeningeal branches of PCA, and meningeal branches of MMA and OA. A detachable Apollo $3 \mathrm{~cm}$ microcatheter was advanced over Mirage 0.08 microguidewire just proximal to the fistulous connections supplied from PCA, and onyx was injected. Control angiogram revealed no more filling of the fistula on the arterial phase. Afterward, a Septer C balloon microcatheter was advanced to select fistulous supply from the MMA and OA and subsequent onyx injection under arterial inflow control after balloon inflation.

Given that there was no more arterial feeders suitable to be engaged with microguidewire/catheter system, a final angiogram was done and revealed a progressive reduction and occlusion of the arteriovenous shunting and some residual filling from other small arterial supplies. Post-procedural, the patient
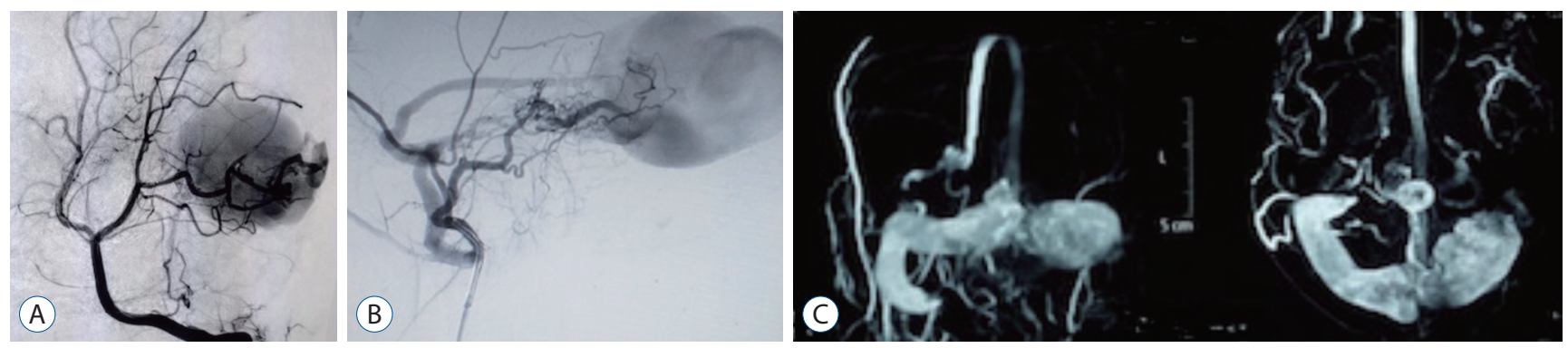

Fig. 1. Case 1. A : Left vertebral artery angiogram (anteroposterior view) demonstrating Cognard type IV DAVF, supplied by pachymeningeal of posterior cerebral artery with early-dilated venous pouch (Transverse sinus). B : Left external carotid angiogram (lateral view) demonstrating Cognard type IV DAVF, supplied by meningeal branches of middle meningeal, posterior auricular and occipital arteries with early-dilated venous pouch (Transverse sinus). C : Magnetic resonance venography (showing hypertrophied dural venous sinuses and thrombosed left sigmoid sinus. DAVF : dural arteriovenous fistula.
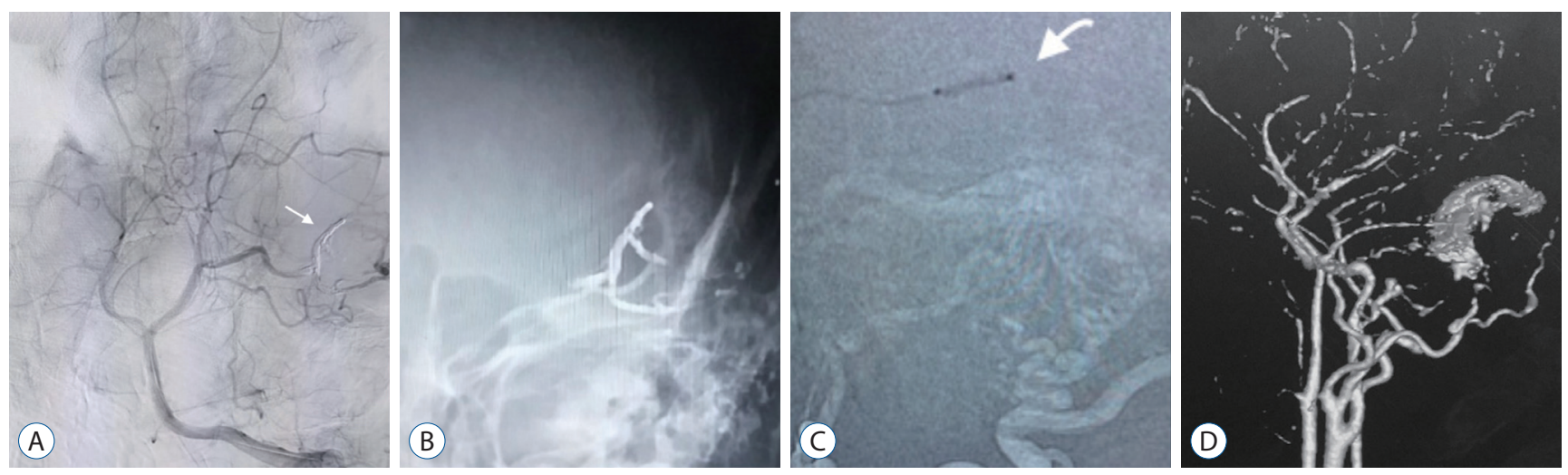

Fig. 2. Case 1. A : Final angiogram showing complete occlusion of the DAVF with onyx (white arrow). B : Fluoroscopic unsubtracted image showing the Onyx cast at the fistula point. C : Road map image showing placement of Scepter C balloon catheter in the middle meningeal artery (white arrow). D : Three-dimensional reconstructed angiographic done after 1 year, showing residual filling of DAVF. DAVF : dural arteriovenous fistula. 
showed significant clinical improvement regarding his cerebellar signs and better neurological functional outcome (mRS 4 to 3). Radiological follow-up after 6 months and 1 year revealed the same residual shunting, and further treatment with TVE is being considered to achieve a complete cure later on (Fig. 2).

\section{Case 2}

Female aged 16 years old manifesting headache and absence fits for 6 months period. A DSA revealed a left occipital high flow PAVF between left hypertrophied PCA (P3 segment) and occipital vein. The draining vein shows aneurysmal dilation measuring $5 \mathrm{~cm}$ in its widest dimension, with subsequent ectasia of the draining sinuses. The decision was taken to use a double microcatheter interlocking coil embolization technique. Two excelsior SL 10 catheters were navigated to the fistulous connection. A subsequent synchronous delivery of two Axium 3D coils from the two catheters was tried many times using variable sized coils. However, the high turbulent flow did not help coils stabilization or their interlocking. The control angiogram, in turn, did not show any significant reduction of the arteriovenous shunting, and the session was aborted (Fig. 3).

Two weeks later, the patient underwent TAE with onyx and arterial inflow control using a single lumen HyperGlide balloon applied proximal to the injecting Marathon flow-directed microcatheter. Onyx embolization of the fistulous junction and distal segment of the arterial feeder was accomplished. Control angiogram revealed complete occlusion of the shunt. Anticoagulants subcutaneous administration was continued for 10 days to avoid rapid and progressive thrombosis. Postprocedural, the patient, showed full resolution of the clinical manifestations, and follow-up radiology after 5 months revealed a significant reduction of the venous aneurysm and complete obliteration of PAVF (Fig. 4).

\section{Case 7}

Female aged 7 years old manifesting epileptic fits for 3 months period. A DSA revealed a left parietal high flow PAVF between left middle cerebral artery (post central branch) and a cortical draining vein. The draining vein shows aneurysmal dilation measuring $4.5 \mathrm{~cm}$ in its widest dimension, with subsequent ectasia of the draining sinuses. The patient underwent TAE with glue to the fistulous connection and feeding artery; a Magic flow-directed microcatheter was navigated over Mirage 0.08 microguidewire to the fistulous connection, and subsequent NBCA glue mixture was injected slowly. The final angiogram showed complete obliteration of the PAVF (Fig. 5).
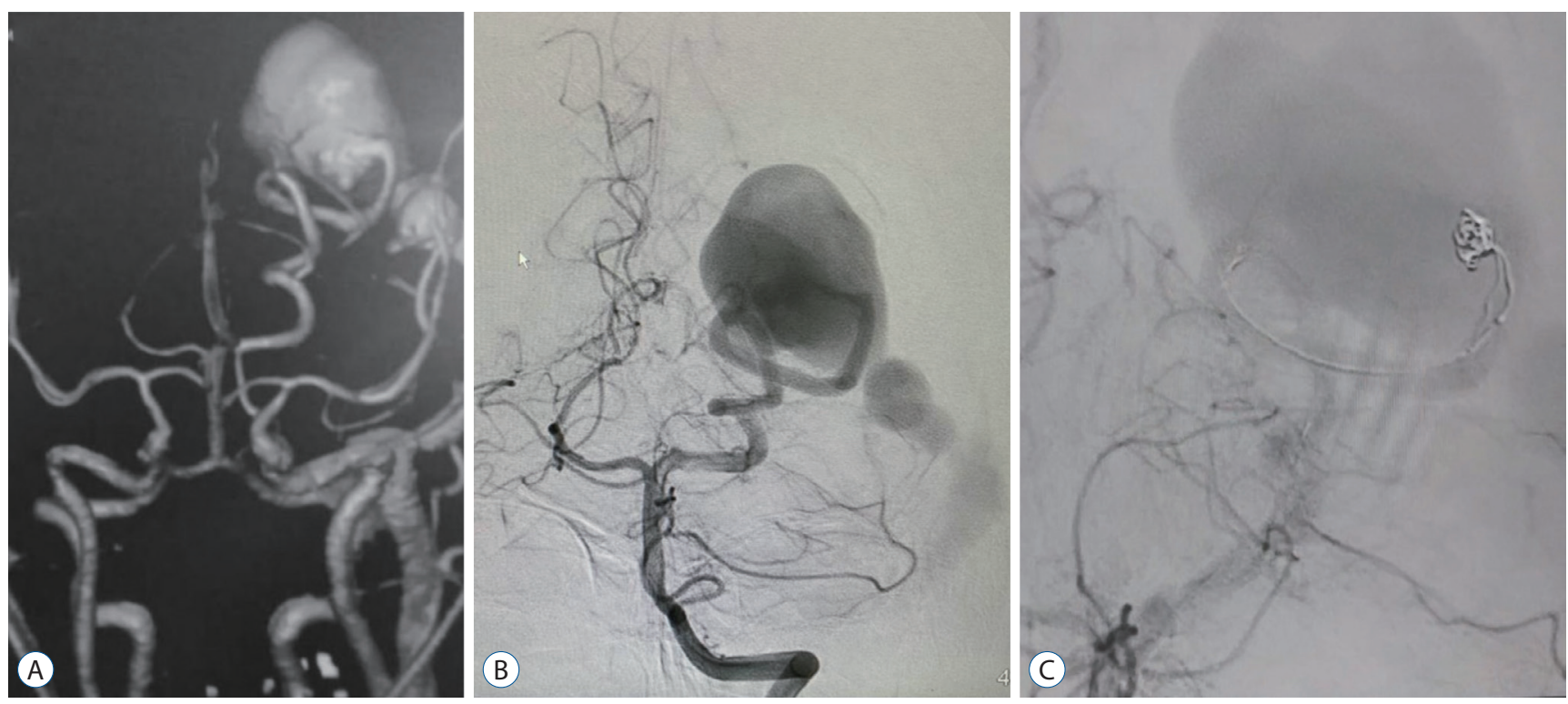

Fig. 3. Case 2. A : Computed tomography angiography showing PAVF, supplied by hypertrophied posterior cerebral artery and aneurysmal dilatation of occipital vein with ectatic dural sinuses. B : Left vertebral artery angiogram (anteroposterior view) demonstrating PAVF, supplied by hypertrophied posterior cerebral artery and aneurysmal dilatation of occipital vein with ectatic dural sinuses. C : Left vertebral artery control angiogram (anteroposterior view) demonstrating attempted coil mass placement in the fistulous connection. PAVF : pial arterioveous fistula. 
Anticoagulants subcutaneous administration was continued for 10 days to avoid rapid and progressive thrombosis. Follow- up after 6 months revealed stable obliteration of the fistula and a significant decrease in venous aneurysm size.
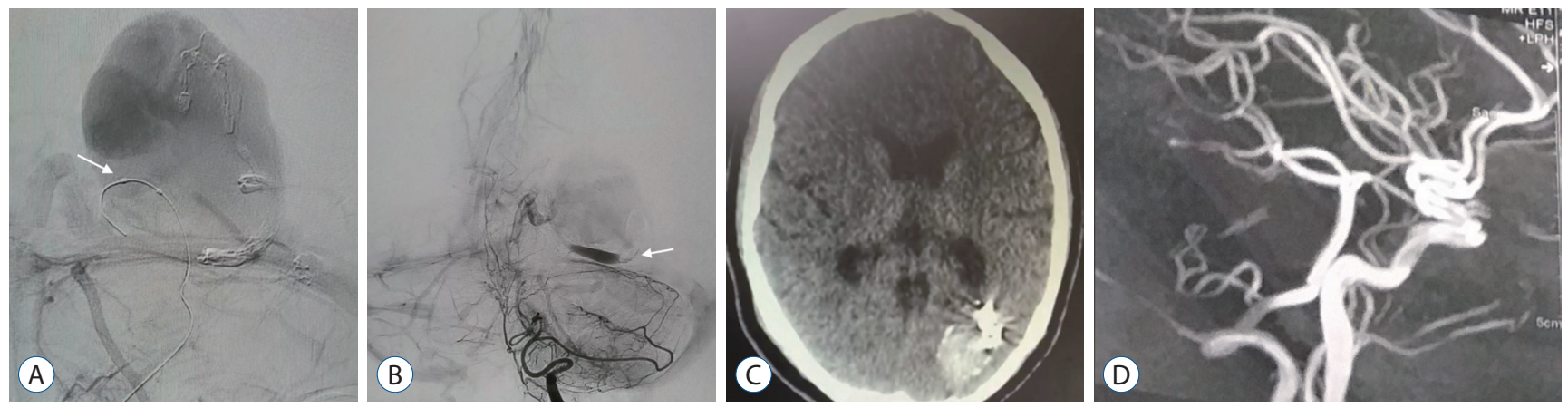

Fig. 4. Case 2. A : Left vertebral artery control angiogram (anteroposterior view) demonstrating onyx embolized arterial feeder and fistulous connection, and deflated HyperGlide balloon proximally placed (white arrow). B : Final angiogram showing complete occlusion of the PAVF with onyx (white arrow). C : Follow up CAT scan of the brain showing onyx and reduced size venous aneurysm with partial thrombosis. D : Three-dimensional reconstructed angiographic done after 6 months, reveal no more filling of the PAVF. PAVF : pial arterioveous fistula.
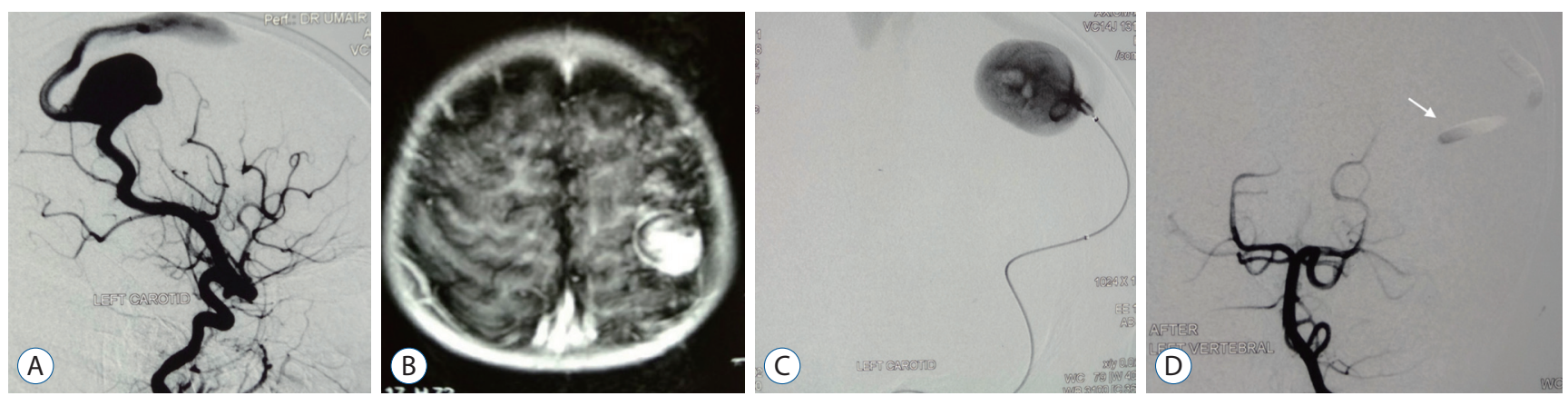

Fig. 5. Case 7. A : Left internal carotid angiogram (anteroposterior view) demonstrating PAVF, supplied by hypertrophied middle cerebral artery and aneurysmal dilatation of cortical draining vein in to superior sagittal sinus. B : Magnetic resonance imaging showing left high parietal PAVF and venous aneurysm. C: Selective angiogram with microcatheter, prior to embolization with n-butyl cyanoacrylate glue mix. D: Final angiogram showing the glue cast (white arrow). PAVF : pial arterioveous fistula.
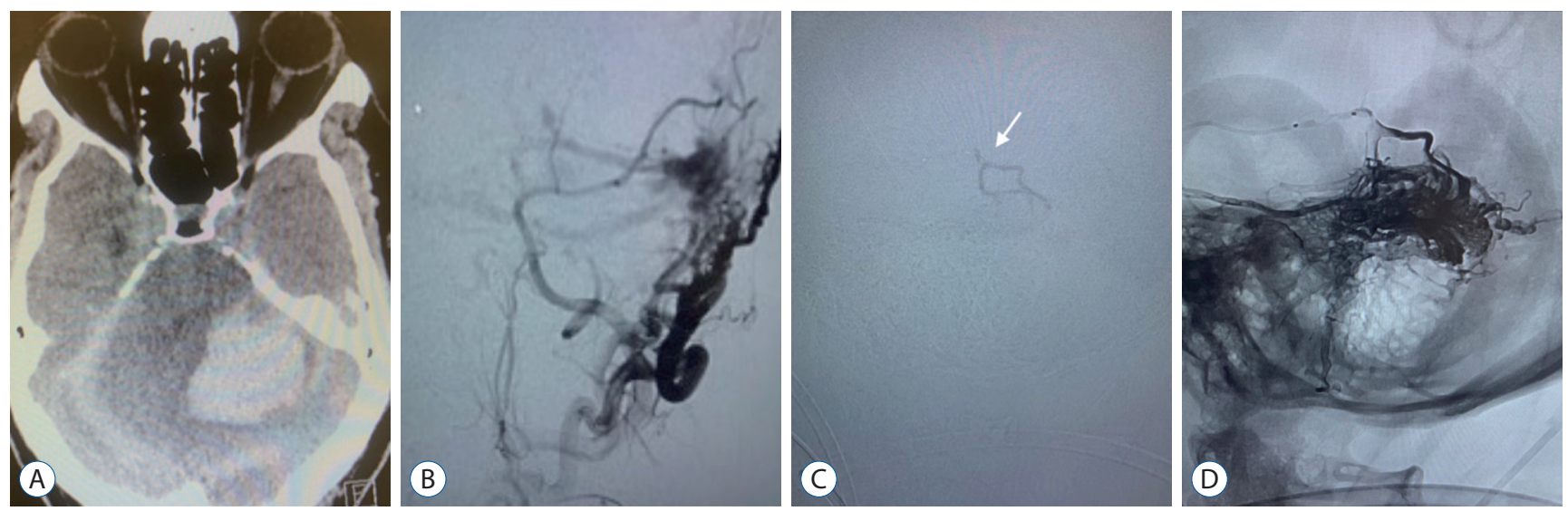

Fig. 6. Case 11. A : CAT scan of the brain showing intracranial hemorrhage secondary to DAVF. B : Left external carotid angiogram (lateral view) demonstrating Cognard type IV DAVF, supplied by meningeal branches of middle meningeal, posterior auricular and occipital arteries draining into transverse sinus. C : Roadmap image showing onyx injection from the microcatheter (white arrow). D : Fluoroscopic unsubtracted roadmap image showing the onyx injection in to the DAVF. DAVF : dural arteriovenous fistula. 


\section{Case 11}

Male aged 55 years old was complaining of headache and tinnitus over 6 months period. The patient presented at the hospital with a disturbed conscious level, and a primary CAT scan brain revealed ICH. Surgical evacuation of the hematoma was done. Later on, DSA showed left transverse sinus Congard type III DAVF supplied by left MMA, internal maxillary artery, and OA meningeal branches. It drained into the transverse sinus, which was ectatic and associated with cortical venous reflux. The patient underwent TAE with onyx and arterial inflow control using a Scepter C balloon catheter, allowing better penetration of onyx. The ICA control angiogram revealed disappeared arteriovenous shunting (Fig. 6). The patient restored his consciousness postprocedural, and follow-up confirmed stable obliteration of the fistula.

\section{DISCUSSION}

\section{Treatment of high flow and aggressive intracra- nial AVFs}

High flow and aggressive intracranial AVFs are usually associated with venous sinus thrombosis or venous hypertension, which in turn might be complicated with $\mathrm{ICH}^{25)}$. In our study, ICH development was evident in six patients (40\%), and that is why early management of these lesions is a must. Surgical treatment is one of the efficient treatment options, in recently published reports; the success rate of surgery for PAVFs and DAVFs was $96.8 \%$ and $83.3 \%$, respectively, with no retreatment needed ${ }^{23,27)}$. However, serious surgical morbidities cannot be neglected. In deeply situated fistulas with large venous varix, surgery could be a hazard. SRS has emerged as a potential treatment option. Though its role has not been conclusively clarified' as it requires a long duration for AVFs obliteration, and it is not preferred for fistulas with cortical venous drainage ${ }^{9,22)}$.

\section{Endovascular embolization for intracranial AVFs}

Endovascular embolization has become a gold standard treatment for intracranial AVFs over the years. Proper understanding of the complex angioarchitecture and variable hemodynamic is fundamental in selecting the most appropriate endovascular route for the obliteration of such type of intracranial fistulas. The transvenous approach is considered in fistulas with numerous and small arterial feeders ${ }^{2)}$. However, in such category of AVFs that we included in this study, which are distantly located with fragile dilated or thrombosed venous outlet (Table 2), the endovenous navigation can be challenging, and the risk of perforation is properly high. TAE was efficient as a complete obliteration of AVFs using sole transarterial approach was $80 \%$ with the overall good functional outcome (mRS 0-2) $93.3 \%$.

\section{Evolution of TAE as a sole treatment and our ex- perience}

TAE is generally safe in our patients; technical complication (Alopecia errata), mostly related to overdose radiation exposure in two consecutive embolization sessions, was documented in only one patient (case 2). It has been reported that rapid progressive thrombosis occurs after the obliteration of AVFs with large venous pouches that can develop post-procedural $\mathrm{ICH}^{10}$. To guard against this devastating problem, we continued the anticoagulants administration regimen for 7-10 days in patients with high flow PAVFs and DAVFs with thrombosed dural sinus, and early follow-up CAT brain was mandatory.

Innovations in embolizing devices and techniques have helped in TAE technical feasibility ${ }^{1,20)}$. That were evident in our included cases. TAE was accomplished in one session in 10 patients $(66.7 \%)$. We used variable liquid embolizing agents (onyx, NBCA glue mixture, and squid) that were efficient in almost all of our cases. We used detachable and flow-directed microcatheters for proper navigation to the fistulous connection and safe delivery of embolizing agents. We applied the arterial inflow control technique in five (33.3\%) of our included patients to guard against migration of such materials to the venous side, which could create an embolus or excessive thrombosis, and to accomplish better penetration of the embolizing material to the fistulous connection. We used singlelumen balloons and double-lumen balloons for that purpose (Table 2). Technical failure was documented in only one of our patients. We tried to apply an interlocking double microcatheter technique in (case 2) to achieve obliteration of the fistulous connection. Unfortunately, that was not successful as we described before. An important factor we did recognize from that two centers' experience is that technical expertise played an important role in choosing the embolizing transarterial devices and techniques. 
The residual was detected on DSA in only four patients (25\%) after one session of TAE. One of them underwent another session of TAE. In the other three cases, we did consider using the transvenous approach later on. In compliance with no more arterial feeders suitable to seek, there was a significant reduction of the arteriovenous shunting and the venous outlet size in those cases, allowing more relative feasibility and safer circumstances to use the transvenous approach.

\section{Limitations}

Our study has some limitations; first, it is retrospective which might be prone to selection bias, and second, the variable angioarchitecture of the lesions, the different techniques applied, and the embolizing materials used might limit the analysis.

\section{CONCLUSION}

Endovascular embolization via transarterial approach for high flow or aggressive intracranial AVFs is a safe and considerable treatment option, especially for those associated with venous outlet ectasia and large venous varix or aneurysm that are challenging and relatively high-risk for TVE. In case of incomplete endovascular occlusion with TAE, the downgrading of these fistulas can be achieved, creating better circumstances for other complementary therapeutic options.

\section{CONFLICTS OF INTEREST}

No potential conflict of interest relevant to this article was reported.

\section{INFORMED CONSENT}

This type of study does not require informed consent.

\section{AUTHOR CONTRIBUTIONS}

\author{
Conceptualization : MAD \\ Data curation : MAD, SA, AEE
}

Formal analysis : MAD, SA, AEE

Funding acquisition : MAD

Methodology : MAD

Project administration : MAD

Visualization: MAD, SA, AEE

Writing - original draft : MAD, SA, AEE

Writing - review \& editing : MAD, SA, AEE

\section{ORCID}

Mohamed Adel Deniwar https://orcid.org/0000-0002-6337-4072

Saima Ahmad https://orcid.org/0000-0002-5022-477X

Ashraf Ezz Eldin https://orcid.org/0000-0002-5703-870X

\section{References}

1. Alturki AY, Enriquez-Marulanda A, Schmalz P, Ogilvy CS, Thomas AJ : Transarterial onyx embolization of bilateral transverse-sigmoid dural arteriovenous malformation with transvenous balloon assist-initial U.S. experience with copernic RC venous remodeling balloon. World Neurosurg $109:$ 398-402, 2018

2. Baharvahdat H, Ooi YC, Kim WJ, Mowla A, Coon AL, Colby GP : Updates in the management of cranial dural arteriovenous fistula. Stroke Vasc Neurol 5 : 50-58, 2019

3. Bhattacharya JJ, Thammaroj J : Vein of galen malformations. J Neurol Neurosurg Psychiatry 74 Suppl 1(Suppl 1) : i42-i44, 2003

4. Biondi A, Casasco A, Houdart E, Gioino C, Sourour N, Vivas E, et al. : Evolution of angiographic signs of venous hypertension and clinical signs of intracranial hypertension in intracranial dural arteriovenous fistulas. J Neuroradiol 26 : 49-58, 1999

5. Borden JA, Wu JK, Shucart WA : A proposed classification for spinal and cranial dural arteriovenous fistulous malformations and implications for treatment. J Neurosurg 82 : 166-179, 1995

6. Cognard C, Gobin YP, Pierot L, Bailly AL, Houdart E, Casasco A, et al. : Cerebral dural arteriovenous fistulas: clinical and angiographic correlation with a revised classification of venous drainage. Radiology 194 : 671-680, 1995

7. Cooke D, Tatum J, Farid H, Dowd C, Higashida R, Halbach V : Transvenous embolization of a pediatric pial arteriovenous fistula. J Neurointerv Surg $4:$ e14, 2012

8. Gandhi D, Chen J, Pearl M, Huang J, Gemmete JJ, Kathuria S : Intracranial dural arteriovenous fistulas: classification, imaging findings, and treatment. AJNR Am J Neuroradiol 33 : 1007-1013, 2012

9. Goel A, Jain S, Shah A, Rai S, Gore S, Dharurkar P : Pial arteriovenous fistula: a brief review and report of 14 surgically treated cases. World Neurosurg 110 : e873-e881, 2018 
10. Gonzalez LF, Chalouhi N, Jabbour P, Teufack S, Albuquerque FC, Spetzler RF : Rapid and progressive venous thrombosis after occlusion of highflow arteriovenous fistula. World Neurosurg 80 : e359-e365, 2013

11. Hetts SW, Keenan K, Fullerton HJ, Young WL, English JD, Gupta N, et al. : Pediatric intracranial nongalenic pial arteriovenous fistulas: clinical features, angioarchitecture, and outcomes. AJNR Am J Neuroradiol 33 : 1710-1719, 2012

12. Hoh BL, Putman CM, Budzik RF, Ogilvy CS : Surgical and endovascular flow disconnection of intracranial pial single-channel arteriovenous fistulae. Neurosurgery 49 : 1351-1363; discussion 1363-1364, 2001

13. Jabbour P, Tjoumakaris S, Chalouhi N, Randazzo C, Gonzalez LF, Dumont $A$, et al. : Endovascular treatment of cerebral dural and pial arteriovenous fistulas. Neuroimaging Clin N Am 23 : 625-636, 2013

14. Kirsch M, Henkes H, Liebig T, Weber W, Esser J, Golik S, et al. : Endovascular management of dural carotid-cavernous sinus fistulas in 141 patients. Neuroradiology $48:$ 486-490, 2006

15. Koebbe CJ, Singhal D, Sheehan J, Flickinger JC, Horowitz M, Kondziolka $D$, et al. : Radiosurgery for dural arteriovenous fistulas. Surg Neurol 64 : 392-398; discussion 398-399, 2005

16. Kwon BJ, Han MH, Kang HS, Chang KH : MR imaging findings of intracranial dural arteriovenous fistulas: relations with venous drainage patterns. AJNR Am J Neuroradiol 26 : 2500-2507, 2005

17. Lasjaunias P, Manelfe C, Chiu M : Angiographic architecture of intracranial vascular malformations and fistulas--pretherapeutic aspects. Neurosurg Rev 9 : 253-263, 1986

18. Lekkhong E, Pongpech S, Ter Brugge K, Jiarakongmun P, Willinsky R, Geibprasert $S$, et al. : Transvenous embolization of intracranial dural arteriovenous shunts through occluded venous segments: experience in 51 Patients. AJNR Am J Neuroradiol 32 : 1738-1744, 2011

19. Liu CA, Chen HC, Luo CB, Guo WY, Mu-Huo Teng M, Chen HH, et al. : Dural sinus malformation with arteriovenous fistulae in a newborn: positive outcome following endovascular management. J Chin Med Assoc
75 : 43-46, 2012

20. Lv $X$, Chen $X, G e H, H e ~ H$, Jiang C, Li Y : Adjunct to embolize the highflow fistula part of arteriovenous malformation using a double-lumen balloon catheter. World Neurosurg 96 : 370-374, 2016

21. Maejima R, Ohshima T, Miyachi S, Matsuo N, Kawaguchi R, Takayasu M : Neonatal intracranial pial arteriovenous fistula treated with endovascular embolization: a case report. World Neurosurg 118 : 261-264, 2018

22. Mohammed N, Hung YC, Xu Z, Starke RM, Kano H, Lee J, et al. : A propensity score-matched cohort analysis of outcomes after stereotactic radiosurgery in older versus younger patients with dural arteriovenous fistula: an international multicenter study. World Neurosurg 125 : e1114-e1124, 2019

23. Oh SH, Choi JH, Kim BS, Lee KS, Shin YS: Treatment outcomes according to various treatment modalities for intracranial dural arteriovenous fistulas in the onyx era: a 10-year single-center experience. World Neurosurg 126 : e825-e834, 2019

24. Pan L, Wen JP, Ma LT : Differences between CS-DAVF and TCCF--to reveal and redefine CS-DAVF. Chin Neurosurg J $4: 26,2018$

25. Qureshi AM, Bhatia K, Kostynskyy A, Krings T : Clinical and angioarchitectural features of ruptured dural arteriovenous fistulas. World Neurosurg 147 : e476-e481, 2021

26. Viñuela F, Drake CG, Fox AJ, Pelz DM : Giant intracranial varices secondary to high-flow arteriovenous fistulae. J Neurosurg 66 : 198-203, 1987

27. Yang WH, Lu MS, Cheng YK, Wang TC : Pial arteriovenous fistula: a review of literature. Br J Neurosurg 25 : 580-585, 2011

28. Yuki I, Kim RH, Duckwiler G, Jahan R, Tateshima S, Gonzalez N, et al. : Treatment of brain arteriovenous malformations with high-flow arteriovenous fistulas: risk and complications associated with endovascular embolization in multimodality treatment. Clinical article. J Neurosurg $113: 715-722,2010$ 